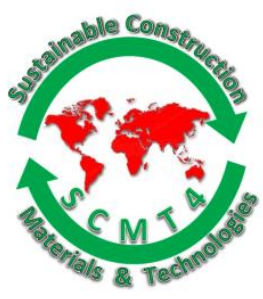

\title{
Engineering Properties of Dredged Materials Stabilized with Fly Ash
}

\author{
Hua Yu ${ }^{1}$, Jie Yin ${ }^{2}$, Ali Soleimanbeigi ${ }^{3 a}$, William J. Likos ${ }^{3 b}$, and Tuncer B. Edil ${ }^{4}$ \\ ${ }^{I}$ Civil and Architectural Engineering, University of Wyoming, Laramie, WY 82701, USA. \\ Email: 〈hyu3@uwyo.edu> \\ ${ }^{2}$ Department of Civil engineering, Jiangsu University, Zhenjiang 212013, China. \\ Email: <yinjie@ujs.edu.cn> \\ ${ }^{3}$ Geological Engineering Department, University of Wisconsin-Madison, Madison, WI 53706, USA. \\ ${ }^{3 a}$ Email: 〈soleimanbeig@wisc.edu>, ${ }^{3 b}$ Email: 〈likos@wisc.edu> \\ ${ }^{4}$ Recycled Materials Resource Center- $3{ }^{\text {rd }}$ Generation (RMRC-3G), University of Wisconsin-Madison, \\ Madison, WI 53706, USA. Email: 〈tbedil@wisc.edu>
}

\begin{abstract}
A series of laboratory tests were conducted on the raw dredged materials (RDMs) stabilized with different fly ash contents (i.e., 10\%, 20\%, and 30\%, by weight of dry soil) and curing times (i.e., 2 hours, 7 days, and 28 days). Results showed that increasing fly ash content decreased the plasticity index and improved engineering properties of RDM. Increasing fly ash content from $0 \%$ to $30 \%$ decreased the plasticity index from $19.3 \%$ to $9.5 \%$, decreased the optimum water content from $30 \%$ to $23 \%$, and increased the maximum dry unit weight from $12.9 \mathrm{kN} / \mathrm{m}^{3}$ to $13.9 \mathrm{kN} / \mathrm{m}^{3}$. Both fly ash content and curing time affected engineering properties of stabilized dredged materials (SDMs). Increasing fly ash content from $0 \%$ to $30 \%$ at 28 -day curing time increased the California bearing ratio (CBR) from 1.5 to 21.4, and increased the undrained shear strength from $240 \mathrm{kPa}$ to $713.8 \mathrm{kPa}$. For specimens with $30 \%$ fly ash content, increasing curing time from 2 hours to 7 days resulted in an increase of CBR from 7.8 to 20.0 as well as an increase of undrained shear strength from $293 \mathrm{kPa}$ to $499 \mathrm{kPa}$. From the results of this study, SDM with no less than $10 \%$ fly ash and curing time longer than 7 days content is recommended as subbase or subgrade fill in roadway construction.
\end{abstract}

\section{INTRODUCTION}

Around 300-million cubic yards of sediments have to be dredged in US to maintain or deepen navigation channels, anchorages or berthing areas for the safe passage of boats and ships [Childs 2015; Katsiaras et al. 2015]. Traditional dredging methods discharge sediments into oceans, rivers, lakes, wetlands, estuaries, or confined disposal facilities (CDFs). Particularly, about 2-3 million cubic yards of sediments are dredged annually in the Great Lakes Region and half of which are placed in CDFs. Meanwhile, many existing CDFs that serve ports are at or near their capacity [Clark and Knight 2013].

Beneficial use of raw dredged materials (RDMs) has become a viable alternative to traditional "dredge and dispose" methods [Childs 2015]. RDMs can be used for beach nourishment, capping, land creation and 
improvement, habitat creation or restoration, replacement fill, construction fill, and for topsoil enhancement [Limeira et al. 2012]. However, the frequency of beneficial use of RDMs in the US at present is only about $20 \%$. The estimated beneficial use of RDMs has great potential ranging between 33-73\% [Childs 2015].

The majority of the RDMs in the CDFs are typically classified as low plasticity silt (ML), high plasticity silt $(\mathrm{MH})$, high plasticity organic $(\mathrm{OH})$, and high plasticity clay $(\mathrm{CH})$ soil by the Unified Soil Classification System (USCS) indicating that RDMs are among the poorest earthwork materials (USBR 1963; Grubb et al. 2006). Therefore, to improve the engineering properties of RDMs, pozzolanic materials such as lime, cement, and fly ash (FA) may be blended with RDMs to produce stabilized dredged materials (SDMs). The engineering properties and general feasibility of using RDMs stabilized with different cementitious materials have been demonstrated through laboratory tests [Maher et al. 2006; Grubb et al. 2010; Kim et al. 2010] and field tests [Sadat Associates Inc. 2001].

The use of FA as a binder is attractive because FA is an industrial by-product that is relatively inexpensive compared with cement and lime [Tastan et al. 2001]. About 50-million tons of FA is produced annually in the United States out of which over 20-million tons are used in engineering applications [ACAA 2014]. Self-Cementing Class C FA, which has relatively high CaO content (compared with Class F FA), has been shown to significantly improve the engineering properties of both inorganic soils [Prabakar et al. 2004; Edil et al. 2006] and organic soils [Tastan et al. 2011].

This paper describes the effects of curing time and fly ash content on index and engineering properties of RDMs stabilized with self-cementing Class C FA for potential use in pavement applications. Atterberg limits, compaction properties, California bearing ratio (CBR), shear strength, and durability of RDMs and SDMs were evaluated systematically at different FA contents and curing times. Practical recommendations were made from the test results.

\section{MATERIALS}

A bulk of RDM sample was obtained from a CDF located at the south end of Milwaukee Harbor. The RDM sample had an in-situ water content of 67.3\% which was obtained per ASTM D2216. The Atterberg limits including the plastic limit (PL) and liquid limit (LL) measured following ASTM D4318 are respectively $42.2 \%$ and $61.5 \%$. The RDM sample consists of $96.6 \%$ fine particles and 3.4\% sand and according to the United Soil Classification System (USCS), the RDM sample is classified as MH. The organic content for the RDM sample obtained per ASTM D2974 is $9.8 \%$. The specific gravity $\left(G_{\mathrm{s}}\right)$ measured according to ASTM D854 is 2.59 which is within the range of $G_{\mathrm{s}}$ for fine-grained soils with organic contents (Huang et al. 2009).

Compaction properties of the RDM sample were obtained using a Harvard Miniature compactor following the standard compaction method per ASTM D698. Maximum dry unit weight $\left(\gamma_{\text {dmax }}\right)$ is $12.9 \mathrm{kN} / \mathrm{m}^{3}$ and the optimum water content $\left(w_{\text {opt }}\right)$ is $30 \%$. The CBR value measured per ASTM D1883 is as low as 1.5 and the unconfined compressive strength $\left(\mathrm{q}_{\mathrm{u}}\right)$ measured per ASTM D2166 is $27.7 \mathrm{kPa}$ indicating that the RDM sample is a poor earthwork material and its engineering properties need to be improved.

The self-cementing FA sample to stabilize RDM for this study was obtained from the Oak Creek power plant in Oak Creek, Wisconsin. The fly ash is classified as Class C according to ASTM C618.

\section{METHODS}

According to ASTM D7762, testing procedures for mechanical properties of stabilized dredged materials (SDMs) using Class C FA include CBR, resilient modulus, unconfined compressive strength, and freezethaw tests. The RDM sample was stabilized with $10 \%, 20 \%$, and $30 \%$ by weight of FA and the specimens 
were respectively designated as SDM-10FA, SDM-20FA, and SDM-30FA. Effects of curing time on Atterberg limits, compaction properties, undrained shear strength, freeze-thaw durability, unconfined compressive strength, CBR, and resilient modulus of the SDM specimens were also evaluated.

For a given FA content, after thoroughly mixing FA with RDM, each mixture was subdivided into 3 groups to evaluate the effect of curing time on the index and engineering properties (i.e. curing after 2 hours, 7 days and 28 days). A summary of the testing program on SDM specimens including the number of specimens for each test and the corresponding ASTM or AASHTO testing standard followed is presented in Table 1 .

\section{Table 1. Summary of Testing Program}

\begin{tabular}{|c|c|c|c|c|c|c|c|c|c|c|c|}
\hline \multirow{3}{*}{ Testing Program } & \multirow{3}{*}{ Standards } & \multicolumn{10}{|c|}{ Numbers of Samples } \\
\hline & & \multicolumn{4}{|c|}{ Curing Time: $2 \mathrm{~h} *$} & \multicolumn{3}{|c|}{ Curing Time: $7 \mathrm{~d}$} & \multicolumn{3}{|c|}{ Curing Time: $28 \mathrm{~d}$} \\
\hline & & $\mathrm{RDM}$ & $\begin{array}{c}\text { SDM } \\
- \\
10 \mathrm{FA} \\
\end{array}$ & $\begin{array}{c}\text { SDM } \\
- \\
20 \mathrm{FA} \\
\end{array}$ & $\begin{array}{c}\text { SDM } \\
- \\
30 \mathrm{FA} \\
\end{array}$ & $\begin{array}{c}\text { SDM } \\
- \\
10 \mathrm{FA} \\
\end{array}$ & $\begin{array}{c}\text { SDM } \\
- \\
20 \mathrm{FA} \\
\end{array}$ & $\begin{array}{c}\text { SDM } \\
- \\
30 \mathrm{FA} \\
\end{array}$ & $\begin{array}{c}\text { SDM } \\
- \\
10 \mathrm{FA} \\
\end{array}$ & $\begin{array}{c}\text { SDM } \\
- \\
20 \mathrm{FA} \\
\end{array}$ & $\begin{array}{c}\text { SDM } \\
- \\
30 \mathrm{FA} \\
\end{array}$ \\
\hline Atterberg Limits & ASTM D4318 & 1 & 1 & 1 & 1 & 1 & 1 & 1 & 1 & 1 & 1 \\
\hline Compaction & ASTM D698 & 1 & 1 & 1 & 1 & - & - & - & - & - & - \\
\hline Triaxial UU Test & ASTM D2850 & 3 & 3 & 3 & 3 & 3 & 3 & 3 & 3 & 3 & 3 \\
\hline Freeze-thaw test & ASTM D560 & 3 & 3 & 3 & 3 & - & - & - & - & - & - \\
\hline UC strength Test & ASTM D2166 & 3 & 3 & 3 & 3 & - & - & - & - & - & - \\
\hline CBR & ASTM D1883 & 1 & 1 & 1 & 1 & 1 & 1 & 1 & 1 & 1 & 1 \\
\hline
\end{tabular}

*h=hour, $d=$ days

Atterberg Limits Test. Atterberg limit tests are conducted to obtain basic index information about the finegrained fraction of soils or to indirectly estimate strength and compressibility characteristics. Common Atterberg limits including the liquid limit (LL) and plastic limit (PL) can be used to assess the amount of dewatering needed before RDM can be handled and processed. The LL, PL, and corresponding plasticity index $(\mathrm{PI}=\mathrm{LL}-\mathrm{PL})$ are commonly used when investigating DM in harbors and CDFs or for evaluating suitability of any raw construction material in roadway construction. Following ASTM D4318, air-dried RDM samples passing through the \#40 sieve (with $0.475-\mathrm{mm}$ opening size) were used for the Atterberg limit tests. Different amounts of tap water were separately added to the RDM, SDM-10FA, SDM-20FA, and SDM-30FA specimens to approximately achieve optimum water content based on Proctor compaction tests. After thoroughly mixing the samples in sealed plastic bags, each sample was divided into three groups and allowed to cure for $2 \mathrm{~h}, 7 \mathrm{~d}$, and $28 \mathrm{~d}$ in a room maintained at $100 \%$ relative humidity and $25{ }^{\circ} \mathrm{C}$. Additional tests were conducted using samples tested immediately after mixing. The 2-h curing time was selected to more accurately represent field construction conditions (Senol et al. 2005). Specimens cured for $7 \mathrm{~d}$ and $28 \mathrm{~d}$ were selected to represent early and relatively long-term curing conditions in roadway construction applications.

Proctor Compaction Test. Compaction tests were conducted to obtain compaction characteristics of the RDM and SDMs including the $\gamma_{\mathrm{dmax}}$ and $w_{\mathrm{opt}}$ and to prepare compacted specimens for subsequent mechanical tests. The compaction tests were conducted using Harvard miniature compaction apparatus (Humboldt 2003). The RDM samples were air-dried and sieved through sieve \#4 (with $4.75 \mathrm{~mm}$ opening size). The fraction of the RDM samples passing through sieve \#4 were blended with different FA contents (i.e., $10 \%, 20 \%$, and $30 \%$ by weight). Five subsamples of each blend were mixed with different water contents (ranging from 10\% to 40\%) and compacted into the steel Harvard miniature compaction mold with a diameter of $33 \mathrm{~mm}$ and height of $71 \mathrm{~mm}$ using a Harvard compactor which produced compaction effort equivalent to the modified Proctor effort according to ASTM D698. 
Unconsolidated Undrained (UU) Strength Test. The shear strength obtained from the UU test is used to evaluate stability of embankment fills in undrained condition. In the UU test, specimens are sheared in compression without drainage by applying constant axial strain rate (ASTM D2850). For each FA content, three replicate specimens were prepared for UU tests. All specimens were prepared using the Harvard miniature compaction method, wrapped and sealed immediately with plastic sheeting to minimize possible moisture change, and cured in the moisture room (with $100 \%$ relative humidity at $25^{\circ} \mathrm{C}$ ) for $2 \mathrm{~h}, 7 \mathrm{~d}$, and $28 \mathrm{~d}$. Cured specimens were tested for undrained shear strength according to ASTM D2850 under $100 \mathrm{kPa}$ isotropic confining pressure.

Freeze-Thaw Cycling Test. To evaluate durability of RDM and SDM samples under cycles of freezing and thawing in the field, the freeze-thaw (F-T) cycling tests were conducted following ASTM D560. Specimens were compacted at $\gamma_{\mathrm{dmax}}$ and $w_{\mathrm{opt}}$ using a Harvard compactor. After sealing with plastic sheeting, the specimens were placed for $24 \mathrm{~h}$ in a freezing cabinet that maintained a constant temperature of $-23^{\circ} \mathrm{C}$. Following the freezing stage, all specimens were placed in the moisture room (with the relative humidity of $100 \%$ and temperature of $25^{\circ} \mathrm{C}$ ) for $24 \mathrm{~h}$. Twelve F-T cycles were considered in this study.

Unconfined Compressive (UC) Strength Test. To investigate how cycles of freezing and thawing and the percentage of FA affect unconfined compressive strength of the SDM specimens, two groups of cured specimens were tested for UC strength: one group was not subjected to F-T cycles and one group was subjected to F-T cycles. For the first group, specimens compacted using a Harvard compactor at optimum water content and maximum dry unity weight were sealed and then placed in moisture room for $24 \mathrm{~d}$. For the second group, samples that had undergone 12 F-T cycles $(24 \mathrm{~d})$ were tested. Strain rate in both cases was $1 \% / \mathrm{min}$ according to ASTM D2166.

CBR Test. The California Bearing Ratio (CBR) test is a penetration test that can be used to evaluate the strength of materials for potential use as pavement subgrade, subbase, and base course material. Following ASTM D1883, air-dried RDM passing through the sieve \#4 and blended with different FA contents (i.e., $0 \%, 10 \%, 20 \%$, and $30 \%$ by weight) were compacted at $\gamma_{\mathrm{dmax}}$ and $w_{\mathrm{opt}}$ in a steel mold with a height of 152 $\mathrm{mm}$ and diameter of $117 \mathrm{~mm}$. Materials were compacted in five layers with 25 blows per layer. Compacted specimens were then sealed with plastic sheeting and placed in the moisture room for $2 \mathrm{~h}, 7 \mathrm{~d}$, and $28 \mathrm{~d}$. Cured specimens were then placed in a water bath for $96 \mathrm{~h}$ for soaking. After soaking, a standard CBR piston penetrated the specimens at a constant rate of $1.27 \mathrm{~mm}(0.05 \mathrm{in}) / \mathrm{min}$.

\section{RESULTS}

Atterberg Limits. Figure 1 shows the results of Atterberg limits tests in the form of the Casagrande Plasticity Chart that plots PI versus LL. The RDM specimen and SDM specimens with FA contents less than $20 \%$ are classified as MH while the SDM specimens with FA content of $30 \%$ are classified as ML. In general, as FA content increases, both LL and PI decrease for all the specimens. There is a linear relationship between LL and PI for the entire suite of RDM and SDM materials having different FA contents and curing times $\left(\mathrm{R}^{2}=0.93\right)$. The slope of trend line of RDM-FA mixtures chart is 0.70 , which indicates this trend line is approximately parallel to the A-line (the slope of A-line is 0.73 ). When FA is blended with soil and water, a series of reactions lead to dissociation of lime $(\mathrm{CaO})$ and the formation of cementitious and pozzolanic gels (Tastan et al. 2011). During the hydration process, free lime reacts pozzolanically with the clay and this reaction reduces clay plasticity (Little and Nair 2009). The Linear relationship between the LL and PI may not be a unique characteristic for SDM. Other stabilized fine-grained soils in the literature showed similar response. 


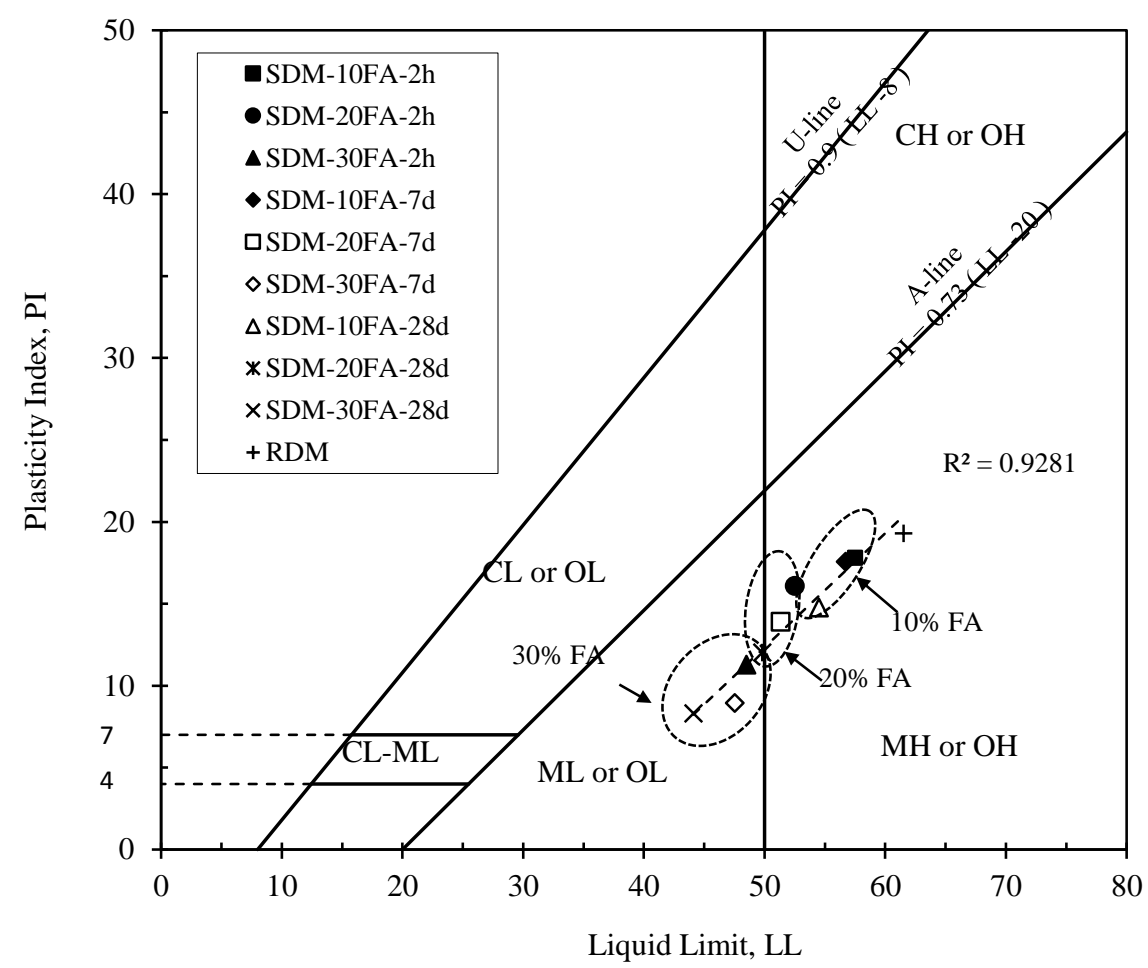

Figure 1. Atterberg limits for RDM and SDM specimens

Compaction Characteristics. Typical bell-shaped compaction curves were obtained for all specimens with different FA contents as shown in figure 2(a). Zero-air-void curve for RDM is also shown in the figure. Increasing the FA content increased the $\gamma_{\mathrm{dmax}}$ and reduced the $w_{\text {opt }}$ [figure 2(b)]. The $\gamma_{\mathrm{dmax}}$ of RDM-FA mixtures is less than $14 \mathrm{kN} / \mathrm{m}^{3}$ which is lower than that of typical compacted soils. The low unit weight makes the RDM and SDM an attractive lightweight material for earthwork applications. The SDM-10FA and SDM-20FA samples had approximately the same $\gamma_{\mathrm{dmax}}\left(13.3 \mathrm{kN} / \mathrm{m}^{3}-13.4 \mathrm{kN} / \mathrm{m}^{3}\right)$ and $w_{\text {opt }}(26.0 \%$ 26.5\%). Subsequent mechanical tests were conducted using specimens compacted at optimum water content and maximum dry unit weight as obtained from the Proctor tests.

UU Shear Strength. Three replicate UU specimens were tested for undrained shear strength $\left(c_{u}\right)$. Figure 3 reports the average $c_{u}$ as a function of FA content for three different curing times. The $c_{u}$ values increased with increasing FA content and curing time. At a given curing time, the $c_{u}$-values increased linearly with increasing FA content. For specimens cured for $2 \mathrm{~h}$, however, the effect of FA content is not as significant. By increasing the curing time, the improvement in $c_{u}$ increases significantly. The percent increase of $c_{u}$ for the SDM for specimens cured for $7 \mathrm{~d}$ ranges from $29 \%$ to $108 \%$ when FA content increases from $10 \%$ to $30 \%$. For the same FA range, the percentage increase for specimens cured for $28 \mathrm{~d}$ ranges from $55 \%$ to $198 \%$. The effect of curing time on $c_{u}$ for specimens with high FA content is more significant than for low FA content. For example, for the SDM-10FA specimen, increasing the curing time from $2 \mathrm{~h}$ to $28 \mathrm{~d}$ increased the $c_{u}$ by $46 \%$. For the SDM-30FA specimen, the $c_{u}$ increased by $144 \%$ over the same curing time frame. At higher FA content, more pozzolanic reactions occur thus more cementitious bonds between the RDM particles are developed over time. Therefore, higher FA contents affect the $c_{u}$ values more greatly as the curing time increases [Horpibulsuk et al. 2013]. 

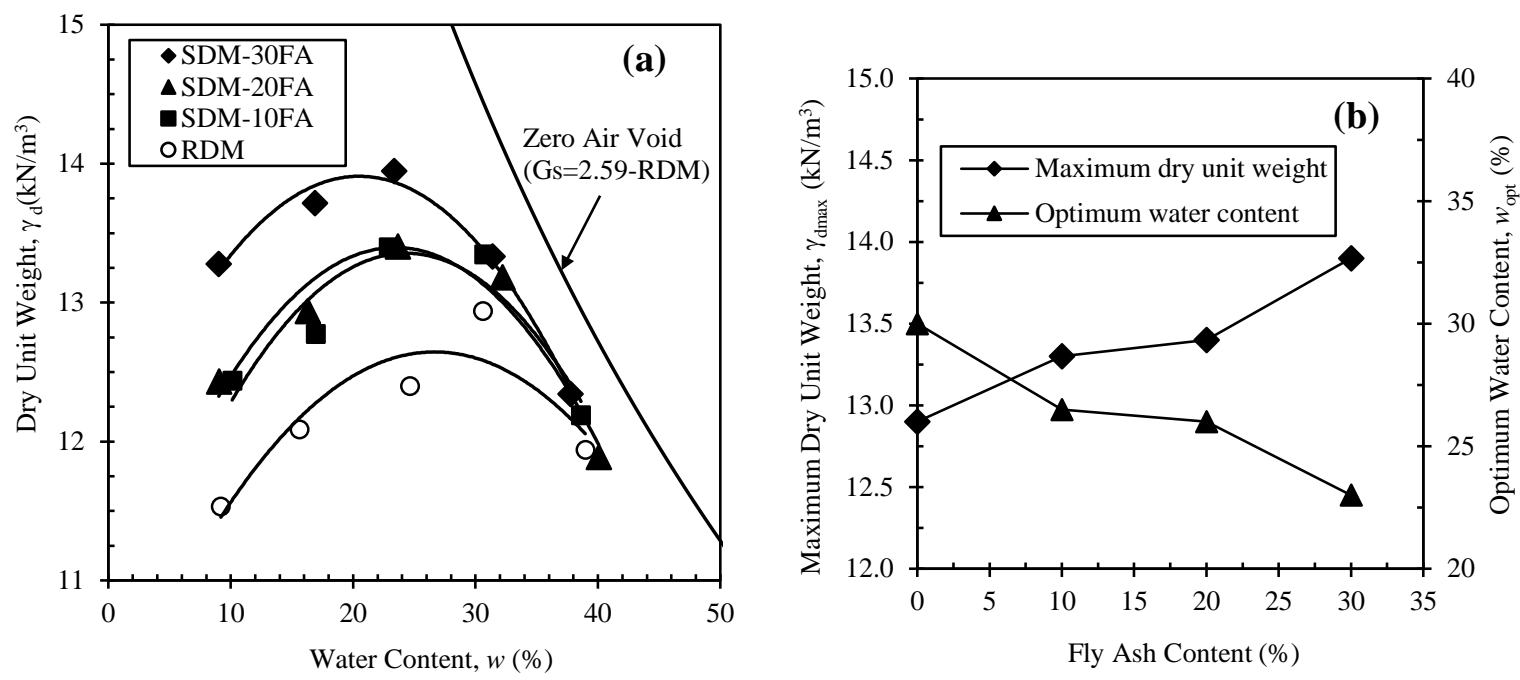

Figure 2. Compaction curves of the RDM and RDM-FA mixtures (a) and optimum water content and maximum dry unit weight versus FA content (b)

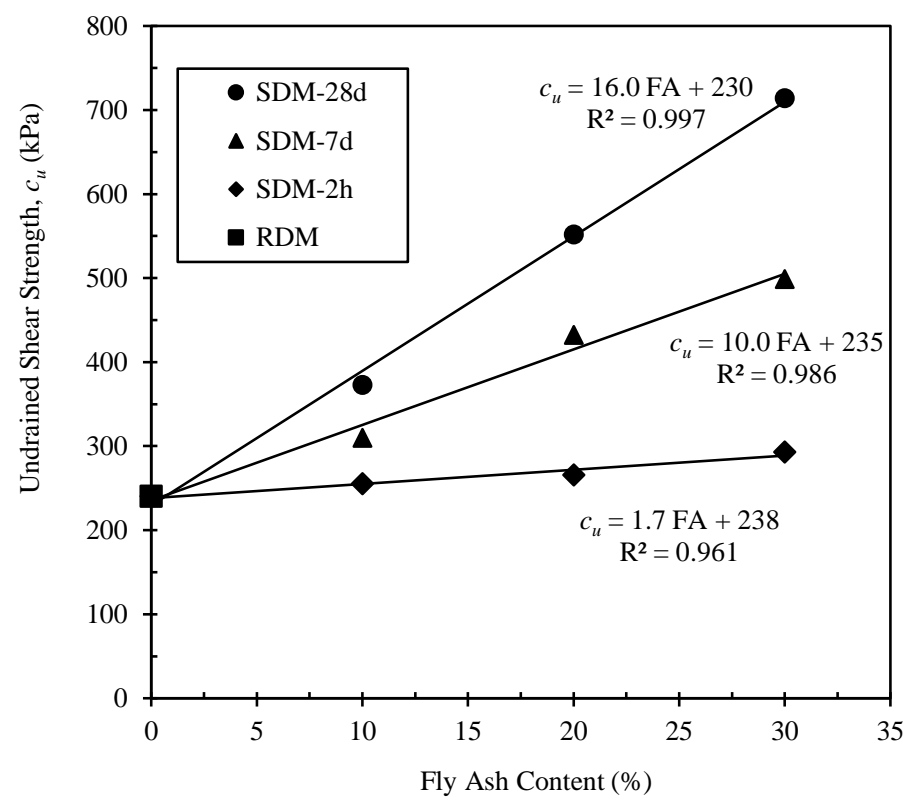

Figure 3. Variation of undrained shear strength with FA content and curing time

Unconfined Compressive Strengths and Freeze and Thaw Cycling. Figure 4 shows the variation of unconfined compressive strengths $\left(q_{u}\right)$ of the RDM and SDM specimens with and without F-T cycles as a function of FA content. Whether or not the specimens are subjected to F-T cycles, increasing FA content increases the $q_{u}$ of the specimens with similar trends. However, the percent increase in $q_{u}$ changes at different FA contents. Increase of FA content from $0 \%$ to $10 \%$ increases the $q_{u}$ by $30 \%$. Increasing FA content from $20 \%$ to $30 \%$ only slightly increases the $q_{u}$ for specimens with and without F-T cycles. Unlike for some fine-grained soils that the benefits accrued by adding FA beyond 20\% diminish [Tastan 2011], increase of FA content in SDM to 30\% increases the $q_{u}$ further by $50 \%$. 


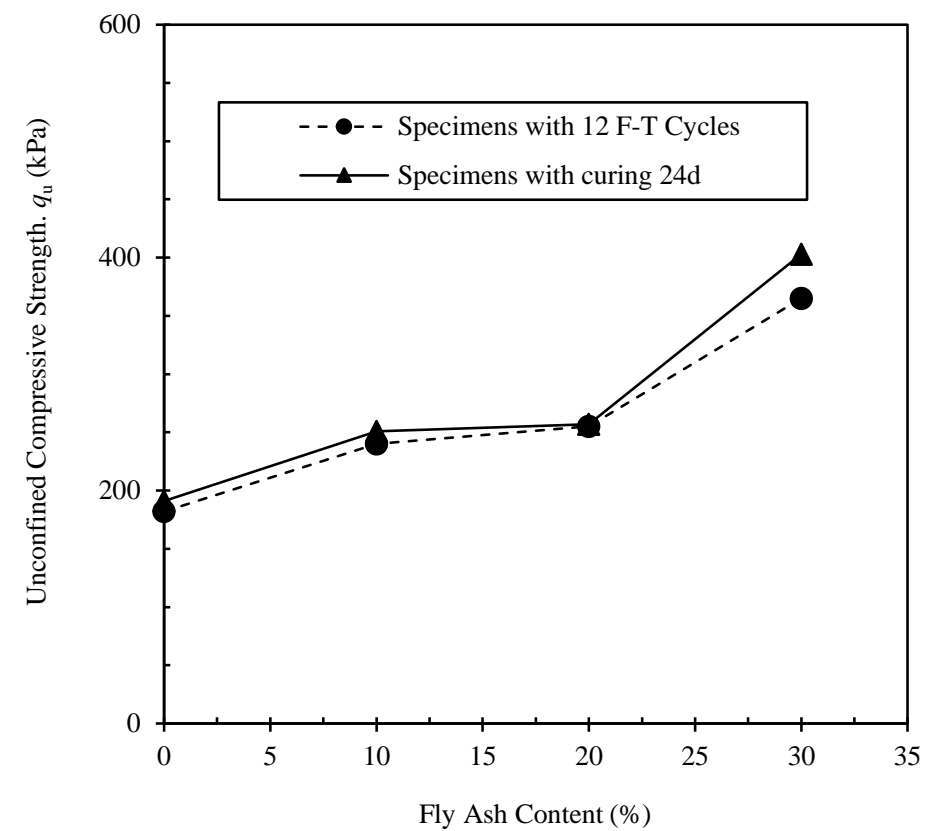

Figure 4. Variation of unconfined compressive strength of SDM specimens with FA content and $\mathrm{F}$ - $\mathrm{T}$ cycles

The $q_{u}$-values for different FA contents only slightly decreased after 12 F-T cycles with an average reduction of $4 \%$ indicating that SDMs are durable under freeze and thaw cycles. However, the unconfined compressive strength of FA-stabilized soft soils was reduced by $20 \%$ and that of FA-stabilized expansive soils was reduced by $40 \%$ after 12 F-T cycles [Bin-Shafique et al. 2010]. The exact reason of this observation was not investigated; it might be due to freezing of pore water, which exerts pressure to expand the volume of the stabilized soil matrix [Toutanji et al. 2004]. This pressure might loosen the cementitious bonding of the particles in the stabilized soils and cause loss of strength.

CBR. Figure 5 shows that CBR increases with increasing FA content and curing time. CBR increases significantly (by 208\% on average) when the curing time of the SDM specimens increases from $2 \mathrm{~h}$ to $7 \mathrm{~d}$. However, curing time after $28 \mathrm{~d}$ only increases the CBR on average by $16 \%$. Figure 5 also shows the CBR of other types of fine-grained soils stabilized with Columbia Class C FA. These specimens were cured for $7 \mathrm{~d}$ in $100 \%$ humidity room before running the CBR tests.

All SDM specimens have relatively low CBR values compared to the other fine-grained soils. One possible reason is that RDM has medium organic content (9.8\%). Due to various factors including lower solids content, higher water content, lower $\mathrm{pH}$, and chemical interferences that occur in the cementing reactions, soils with high organic content have been more difficult to stabilize than soils with low organic content [Janz and Johansson 2002]. CBR values of SDM specimens vary between 10-20 which are comparable to those of compacted silty sand or sand [Rollings and Rollings 1996]. Table 2 summarizes the relative ratings of supporting strengths as a function of CBR for subbase and subgrade soils. Based on the CBR range between 10-20, SDMs are classified as fair to good for subgrade application. Figure 5 shows that the SDM should contain at least $10 \%$ FA and should be cured for at least $7 \mathrm{~d}$ so that the material gains sufficient CBR for subgrade application. 


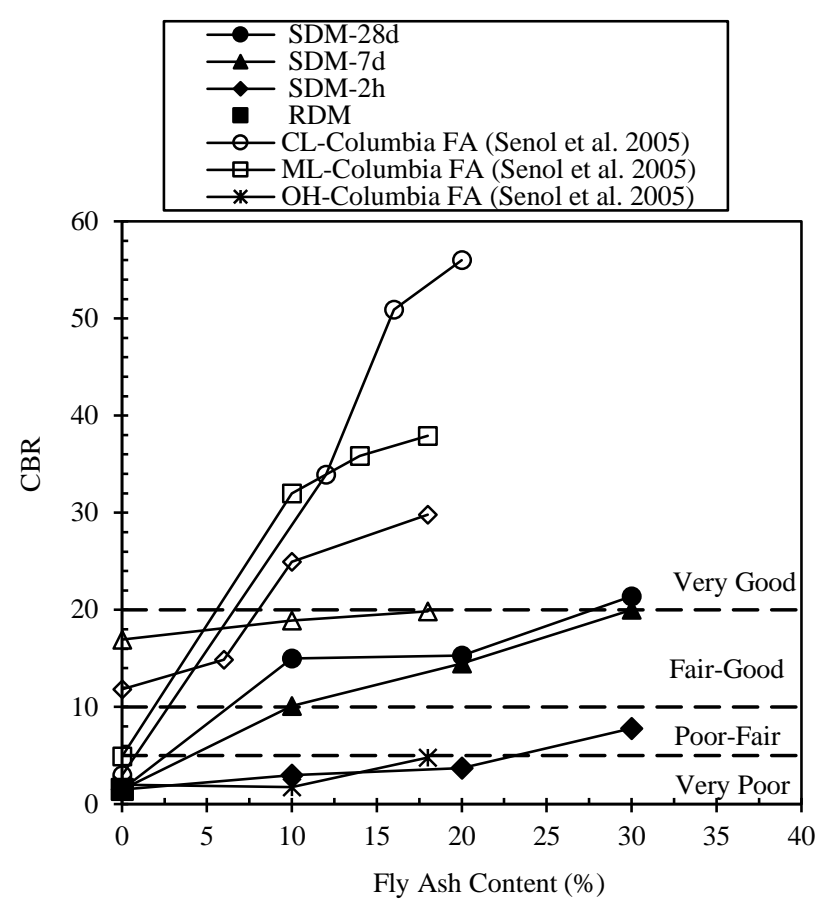

Figure 5. Variation of CBR with FA content

Table 2. Relative CBR Ratings for Subbase and Subgrade [Schaefer et al. 2008]

\begin{tabular}{|c|c|c|}
\hline $\begin{array}{c}\text { CBR } \\
(\%)\end{array}$ & Application & Rating \\
\hline$>80$ & Subbase & Excellent \\
\hline 50 to 80 & Subbase & Very Good \\
\hline 30 to 50 & Subbase & Good \\
\hline 20 to 30 & Subgrade & Very good \\
\hline 10 to 20 & Subgrade & Fair-good \\
\hline 5 to 10 & Subgrade & Poor-fair \\
\hline$<5$ & Subgrade & Very poor \\
\hline
\end{tabular}

\section{CONCLUSION}

In this study, a series of laboratory tests was conducted where RDM-FA mixtures were prepared at different FA contents $(10 \%, 20 \%$, and $30 \%)$ and curing times ( $2 \mathrm{~h}, 7 \mathrm{~d}$, and $28 \mathrm{~d})$ to evaluate how FA and curing time can improve engineering properties of RDMs. Main findings are listed below:

- All the SDM specimens exhibited lower plasticity compared to RDM. Increase of FA content or curing time reduced the PI and LL for SDMs.

- The undrained shear strength $\left(c_{u}\right)$ increased for all SDMs with increasing FA content and curing time. For a given curing time, $c_{u}$ increased linearly with increasing the FA content. The improvement in $c_{u}$ increased significantly as the curing time increased.

- The unconfined compressive strengths $\left(q_{u}\right)$ of the specimens increases with increasing the FA content. The $q_{u}$-values were only slightly decreased after $12 \mathrm{~F}-\mathrm{T}$ cycles with an average reduction of $4 \%$ indicating that SDM in this study is a durable material. 
- CBR of SDM specimens increased with increasing FA content and curing time. CBR of SDM specimens cured for 7 days vary between 10-20 which are comparable to CBR of compacted silty sand or sand, and are classified as fair to good for subgrade application.

In general, use of fly ash to stabilize RDM offers a feasible and effective way for using high volume of dredged materials and reducing the burden of storage and disposal of the fly ash. Economically, coal fly ash stabilization is cheaper than stabilization with the conventional materials such as cement and lime. Based on the results of this study, SDMs with fly ash higher than $10 \%$ and curing time longer than 7 days can be used as roadway subbase or subgrade fill.

\section{ACKNOWLEDGEMENT}

Authors acknowledge support from the National Center for Freight and Infrastructure Research and Education (CFIRE). Authors are also grateful to Isak Frachtman and Sarah Fernholz for their help during the tests. The opinions, findings, conclusions, or recommendations expressed herein are those of the authors and do not necessarily represent the views of the sponsors.

\section{REFERENCES}

Amecrican Coal Aah Associtation (ACAA) (2014). "Benefical use of coal combustion products: an american recyling success story". Farmington Hills, MI. http://www.acaausa.org/Portals/9/Files/PDFs/2013-Production-and-Use-Brochure.pdf, accessed on Jan, 2014

ASTM D2216. (2010). "Standard test methods for laboratory determination of water (moisture) content of soil and rock by mass." ASTM D2216-10, West Conshohocken, Pa.

ASTM D4318. (2010). "Standard test methods for liquid limit, plastic limit, and plasticity index of soils." ASTM 4318-10e1, West Conshohocken, Pa.

ASTM D2974. (2014). " Standard test methods for moisture, ash, and organic matter of peat and other organic soils." ASTM D2974-14, West Conshohocken, Pa.

ASTM D698. (2012). "Standard test methods for laboratory compaction characteristics of soil using standard effort." ASTM D698-12e1, West Conshohocken, Pa.

ASTM D1883. (2014). " Standard test method for california bearing ratio (CBR) of laboratory-compacted soils." ASTM D1883-114, West Conshohocken, Pa.

ASTM D2166. (2013). " Standard test method for unconfined compressive strength of cohesive soil." ASTM D2166/D2166M-13, West Conshohocken, Pa.

ASTM C618. (2012). "Standard specification for coal fly ash and raw or calcined natural pozzolan for use in concrete." ASTM C618-12a, West Conshohocken, Pa.

ASTM D7762. (2011). " Standard practice for design of stabilization of soil and soil-like materials with self-cementing fly ash." ASTM D7762-11, West Conshohocken, Pa.

ASTM D2850. (2007). " Standard test method for unconsolidated-undrained triaxial compression test on cohesive soils." ASTM D2850-03a(2007), West Conshohocken, Pa.

ASTM D560. (1996). " Standard test methods for freezing and thawing compacted soil-cement mixtures." ASTM D560-96, West Conshohocken, Pa.

Bin-Shafique, S., Rahman, K., Yaykiran, M., and Azfar, I. (2010). "The long-term performance of two fly ash stabilized fine-grained soil subbases". Journal of Resources, Conservation and Recycling, 54 (10), 666-672. 
Childs, J. L. (2015). " Dredged material management categories for tracking beneficial use." ERDC TNDOER-R22, http://el.erdc.usace.army.mil/elpubs/pdf/doerr22.pdf, accessed on June, 2015.

Edil, T.B., Acosta, H.A., and Benson, C.H. (2006). "Stabilizing soft fine-grained soils with fly ash", J. Mater. Civ. Eng. 18, SPECIAL ISSUE: Stabilization of Geomedia Using Cementitious Materials, 283294.

Clark, G., and Knight, D. L. (2013) "Beneficial use of dredged material in the Great Lakes." Great Lakes Dreding Team, http://greatlakesdredging.net/files/pdf/2013BeneficialUse-online-FINAL.pdf, accessed on March 15, 2013.

Grubb, D. G., Malasavage, N. E., Smith, C. J., and Chrysochoou, M. (2010). "Stabilized dredged material. II: geomechanical behavior." Journal of Geotechnical and Geoenvironmental Engineering, 136(8), 1025-1036.

Huang, P. T., Patel, M., Santagata, M. C., and Bobet, A. (2009). "Classification of organic soils." Publication report FHWA/IN/JTRP-2008/02 Joint transportation research program Indiana department of transportation and Purdue University West Lafayette Indiana.

Humboldt Mfg. Co. (2003). "Harvard miniature compaction apparatus(H-4165)-Instrcutin Manual." Humboldt Mfg. Co., Norridge, IL, 1-7.

Horpibulsuk, S., Phetchuay, C., Chinkulkijiniwat, A., Cholaphatsorn A. (2013). "Strength development in silty clay stabilized with calcium carbide residue and fly ash. " Soils and Foundations, 53(4), 477-486.

Janz, M., and Johansson, S., (2002). "The functions of different binding agents in deep stabilization. " Swedish Deep Stabilization Research Center Rep. No. 9, Swedish Geotechnical Institute, Linkoping, Sweden.

Katsiaras, N., Simboura, N., Tsangaris, C., Hatzianestis, I., Pavlidou, A., and Kapsimalis, V. (2015). "Impacts of dredged-material disposal on the coastal soft-bottom macrofauna, Saronikos Gulf, Greece." Science of the Total Environment, 508, 320-330.

Kim, Y. T., Ahn, J., Han, W. J., and Gabr, M. A. (2010). "Experimental evaluation of strength characteristics of stabilized dredged soil." Journal of Materials in Civil Engineering, 22(5), 539-544.

Limeira, J., Agullo, L., and Etxeberria, M. (2012). "Dredged marine sand as construction material." European Journal of Environmental and Civil Engineering, 16(8), 906-918.

Little, D. N., and Nair, S. (2009). "Recommended practice for stabilization of subgrade soils and base materials." Contractor's Final Task Report for NCHRP Project 20-07, Texas Transportation Institute, Texas A\&M University, College Station, Texas.

Maher, A., Sarmad, A., and Jafari, M. (2006). "Geotechnical evaluation of stabilized dredged material (SDM) from the New York/New Jersey Harbor." Geo-Environment and Landscape Evolution II, 89, 431-441.

Prabakar, J., Dendorkar, N., Morchhale, R.K. (2004). "Influence of fly ash on strength behavior of typical soils." Constr. Build. Mater. 18 (4), 263-267.

Rollings, M. P., and Rollings, R. S. (1996). "Geotechnical Materials in Construction." Construction series, McGraw-Hill.

Sadat Associates Inc. (2001). "Use of dredged materials for the construction of rodaway embankments." New Jersey Deparment of Transportation, 1-167.

Senol A., Edil, T.B., Bin-Shafique, M.S., Acosta, H.A., and Benson, C.H., 2005, "Soft subgrades' stabilization by using various fly ashes", Resources Conservation and Recycling, 46(4): 365-376. 
Schaefer, V. R., White, D. J., Ceylan, H., and Stevens, L. J. (2008). "Design Guide for Improved Quality of Roadway Subgrades and Subbases." Iowa Highway Research Board (IHRB) Project TR-525.

Tastan, E., Edil, T., Benson, C., and Aydilek, A. (2011). "Stabilization of organic soils with fly ash." $J$. Geotech. Geoenviron. Eng., 137(9), 819-833.

Toutanji, H. N., Delatte, S,. Aggoun, R., and Danson A. (2004) "Effect of supplementary cementitious materials on the compressive strength and durability of short-term cured concrete." Cement and Concrete Research, 34(2), 311-9.

USBR. (1963). "US Department of the Interior, Bureau of Reclamation." Earth manual, Denver. 